\title{
Governança, “Accountability” e Responsividade
}

\author{
Governance, accoutability and responsiveness
}

SÉRGIO DE AZEVEDO*

FÁTIMA ANASTASIA**

RESUMO: Para analisar a institucionalização de canais alternativos de participação na formulação de políticas públicas no estado de Minas Gerais, Brasil, o artigo parte do pressuposto de que a relação entre accountability e responsividade nas chamadas "novas democracias" depende basicamente do projeto de institucionalidade adotado e em sua adequação às condições societárias prevalecentes.

PALAVRAS-CHAVE: Governança, responsabilidade, capacidade de resposta.

ABSTRACT: In order to analyze the institutionalization of alternative channels of participation in public policy making in the state of Minas Gerais, Brazil, the paper starts from the assumption that the relationship between accountability and responsiveness in the so called "new democracies" basically depends on the institutional design adopted and on its adequacy to the prevailing societal conditions.

KEYWORDS: Governance, accountability, responsiveness.

JEL Classification: H1.

\section{INTRODUÇÃO}

Há certo consenso entre estudiosos filiados a diferentes correntes de pensamento sobre a maioria dos Estados nacionais e sub-nacionais, nas últimas duas décadas, especialmente no chamado terceiro mundo, ter perdido sua capacidade de intervenção efetiva, instalando-se uma crise de governança.

Alguns pesquisadores ressaltam que esses constrangimentos à ação governamental possuem características estruturais, ainda pouco sistematizadas e analisadas, comuns às chamadas "novas democracias" que, nos anos oitenta, foram palco de

\footnotetext{
* Pontifícia Universidade Católica/PUC, Minas Gerais. E-mail: azevedo.sergio@uol.com.br; Orcid: 00000002-4266-2120

** Universidade Federal de Minas Gerais/UFMG. E-mail: fatima.anastasia@gmail.com; Orcid: 00000001-5839-9155.
} 
reformas políticas democráticas sem a necessária contrapartida de inovações efetivas na área econômica e social (O’Donnell, 1993).

Outros analistas consideram serem as instabilidades desses Estados decorrentes da "incorporação das massas à dinâmica da competição política antes que se obtivesse estabilidade na institucionalização das regras dessa mesma competição" (Santos, W.G., 1988:112).

Vale lembrar, ainda, as explicações que vinculam as crises institucionais, recorrentes em certas sociedades, à tradição de violações freqüentes das normas (impunidade, corporativismo desregulado, extorsão de renda sob violência, comportamento predatório etc.). Segundo essa vertente, tais fatores vêm comprometendo a credibilidade e a eficácia da lei e maximizando os efeitos perversos oriundos das próprias tentativas de formalização da intervenção estatal, o que tem levado a uma situação de constante imprevisibilidade e de instabilidade das regras, na qual prevalece, de fato, o chamado pretorianismo, ou seja, a lei do mais forte (Huntington, 1979).

Neste trabalho, partimos do suposto de que as relações entre governança, accountability e responsividade nas novas democracias, dependem, fundamentalmente, do desenho institucional a elas conferido e de sua adequação às condições societais (Przeworski, 1991; Lijphart, 1980). Embora governança seja um atributo do Estado e governabilidade um atributo da sociedade, como afirma Fábio Wanderley Reis, consideramos que há uma importante imbricação entre ambos, já que Estado e sociedade só podem ser pensados como entes relacionais. O que significa dizer que só há Estado se houver uma sociedade a ser governada, e que só há sociedade se seus membros conseguirem acordar as regras que presidirão a organização de sua convivência, ou seja, alguma forma de Estado.

Assim, o conceito de governança aqui utilizado não se limita ao formato institucional e administrativo do Estado e à maior ou menor eficácia da máquina estatal na implementação de políticas públicas (Melo,1996; Diniz,1996). Se o conceito de governabilidade remete às condições sistêmicas sob as quais se dá o exercício do poder, ou seja, aos condicionantes do exercício da autoridade política, governança qualifica o modo de uso dessa autoridade. Envolve, portanto, além das questões político-institucionais de tomada de decisões, as formas de interlocução do Estado com os grupos organizados da sociedade, no que se refere ao processo de definição, acompanhamento e implementação de políticas públicas (Melo, 1995; Coelho \& Diniz, 1995).

Se é assim, a natureza da relação entre Estado e sociedade afeta, concomitantemente, os graus e as formas de governança do Estado e de governabilidade da sociedade. Interessa, pois, explorar questões relativas a padrões de articulação e cooperação entre atores sociais e políticos e a arranjos institucionais que coordenam e regulam transações dentro e através das fronteiras dos sistemas político e econômico. Incluem-se aí, "não apenas os mecanismos tradicionais de agregação e articulação de interesses (...), como também redes sociais informais (...), hierarquias e associações de diversos tipos" (Santos, M. H., 1996).

Em suma, a maior ou menor capacidade de governança depende, por um lado, da possibilidade de criação de canais institucionalizados, legítimos e eficientes; de 
mobilização e envolvimento da comunidade na elaboração e implementação de políticas e, por outro, da capacidade operacional da burocracia governamental, seja nas atividades de atuação direta, seja naquelas relacionadas à regulação das políticas públicas.

As formas e os grau de accountability e de responsiveness da ordem política afetam, por sua vez, os padrões de governabilidade vigentes nas diferentes sociedades. Sustentamos que a governabilidade democrática é uma variável dependente da capacidade dos governos de serem responsáveis e responsivos perante os governados.

Segundo Przeworski (1996:25) “... governos são responsáveis quando os cidadãos têm possibilidade de discernir aqueles que agem em seu benefício, e podem lhes impor sanções apropriadas, de modo que os governantes que atuam em prol do benefício dos cidadãos sejam reeleitos, e os que não o fazem sejam derrotados". E governos responsivos são aqueles que promovem os interesses dos cidadãos, escolhendo políticas "que uma assembléia de cidadãos, tão informados quanto o Estado, escolheria por votação majoritária, sob os mesmos constrangimentos institucionais" (Przeworski, 1996:26; Stokes, 1995).

Sabe-se que eleições são instrumentos necessários para a constituição de governos democráticos, mas não suficientes para garantir o controle dos governantes pelos governados (Manin, Przeworski \& Stokes, 2000). Se a representação foi a solução institucional que propiciou a factibilidade da democracia nas sociedades contemporâneas (Dahl, 1982), ela constitui, também, o seu limite, dadas as imperfeições e insuficiências decorrentes dessa solução. O grande desafio que se coloca atualmente, para as democracias novas ou já consolidadas, refere-se ao aperfeiçoamento e ao aprofundamento das instituições democráticas, com vistas a permitir sua operação nos interstícios eleitorais, acoplando aos mecanismos clássicos da representação formas institucionalizadas de participação política, que permitam a ampliação do direito de vocalização das preferências dos cidadãos e o controle público do exercício do poder (Anastasia, 2000). Tal implica um exercício de engenharia institucional que permita transformar a democracia em um jogo iterativo, jogado em múltiplas arenas (Tsebelis, 1990) e em um contexto decisório contínuo (Sartori, 1994).

Baseados nos argumentos de Ferejohn (1997) e de Stark \& Brust (1998), segundo os quais não há incompatibilidade necessária entre autoridade do Estado e accountability ${ }^{1}$, tomamos como objeto de estudo algumas inovações institucionais que vêm sendo experimentadas no Brasil, a partir do final dos anos oitenta, no âmbito dos poderes local e estadual. Nosso intuito é o de analisar os impactos por elas provocados nas formas e nos graus de governança e de governabilidade vigentes.

Vale ressaltar, entre essas inovações, a implementação das chamadas "institui-

\footnotetext{
${ }^{1}$ Esses autores oferecem interessantes análises sobre a relação entre autoridade e responsabilidade, que contrariam, seja "a crença tradicional de que executivos não-limitados têm mais autoridade para executar reformas” (Stark \& Brust, 1998:13), sejam os argumentos que afirmam ser a concentração da autoridade favorável à implementação de mudanças nas políticas públicas, dada a presença de um número menor de "veto players" (Tsebelis, 1997).
} 
ções híbridas", que são "instituições mistas, formadas em parte por representantes do Estado, em parte por representantes da sociedade civil, com poderes consultivos e/ou deliberativos, que reúnem, a um só tempo, elementos da democracia representativa e da democracia direta"(Avritzer, 2000:18). Essas instituições permitem maior participação de grupos organizados da sociedade na elaboração e na fiscalização das políticas públicas. Neste trabalho, pretendemos descrever e analisar algumas "instituições híbridas", tais como os Conselhos Setoriais (CS), o Orçamento Participativo (OP) e novos eventos institucionalizados de interlocução entre o legislativo estadual e setores organizados da sociedade, especialmente os chamados Seminários Legislativos. Procederemos da seguinte forma: na próxima seção analisaremos algumas características dos Conselhos de Políticas Setoriais da Região Metropolitana de Belo Horizonte, assinalando semelhanças encontradas com as experiências de Conselhos desenvolvidas na Metrópole do Rio de Janeiro. Posteriormente, discutiremos sucintamente as potencialidades e os constrangimentos do Orçamento Participativo (OP) de Belo Horizonte, que apresenta fortes similaridades com iniciativas implementadas em outras grandes cidades brasileiras. Por fim, faremos uma breve análise de experiências inovadoras oriundas do poder legislativo de Minas Gerais, buscando o envolvimento de grupos organizados da população na formulação e na fiscalização de políticas regulatórias setoriais. O artigo, na sua parte final, realiza um balanço dessas inovações institucionais no que se refere à accountability e à ampliação da capacidade de resposta do poder público em Minas Gerais.

\section{OS CONSELHOS DE POLÍTICAS SETORIAIS}

O esgotamento do ciclo autoritário-militar (1964-1984), no Brasil, colocou na agenda política o tema da redemocratização da ordem e a retórica da participação popular. Assistiu-se a um conjunto de tentativas, nos anos oitenta, de implementação de "programas participativos", por meio dos quais se buscava conferir centralidade à questão social e incentivar a mobilização dos cidadãos nos esforços de superação das condições adversas de vida urbana que penalizavam contingentes significativos da população do país.

Entretanto, naquele momento, a maioria das experiências colocadas sob a rubrica de programas participativos referia-se ao que denominamos de "participação restrita ou instrumental" 2 , uma modalidade de participação constituída, quase que exclusivamente, por movimentos reivindicativos (associações de bairros e de favelas, movimentos de transporte de uma região, demandas por serviços de saúde, educação etc), cujo objetivo é o de obter do Estado melhorias sócio-econômicas. Em suma, trata-se de organizações típicas de articulação de interesses, orientadas para a produção de "bens coletivos" de natureza negociável (urbanização de fave-

\footnotetext{
${ }^{2}$ Ver, à respeito, Azevedo \& Prates, 1991.
} 
las, construção de creches, escolas, postos de saúde, saneamento básico), nas quais não estão em jogo questões de "princípios" ou de valores, como no caso dos movimentos sociais clássicos.

Por meio desse tipo de iniciativa, o governo buscava alcançar diferentes objetivos: dividir responsabilidades com as comunidades carentes na aplicação de verbas escassas; ampliar os recursos disponíveis, por meio da substituição de parte do capital por mão-de-obra gratuita ou sub-remunerada; aumentar a eficácia na alocação de recursos; elevar o nível de legitimação do governo e/ou das burocracias públicas, entre outros (Azevedo \& Prates,1991).

Já a participação das organizações associativas de baixa renda era motivada por interesses bastante pragmáticos, ou seja, era vista como forma de conseguir do Poder Público recursos adicionais àqueles eventualmente obtidos com os programas tradicionais, o que não significa que as práticas associativas desse tipo não possam trazer ganhos no campo dos direitos da cidadania.

Outra modalidade de envolvimento comunitário - que denominamos de "participação ampliada" — atrai, além das organizações reivindicativas acima mencionadas, os "movimentos sociais clássicos". Do ponto de vista sociológico, esses movimentos podem ser definidos como organizações coletivas orientadas primariamente para fins de natureza normativa ou ideológica, ou seja, para assegurar ou transformar valores básicos que regulam a ordem institucional de uma sociedade. Enquadram-se nessa classificação os movimentos ambientalistas, de gênero, contra a discriminação racial e pacifistas, entre outros. Isso não significa que esses movimentos não possam se envolver em atividades voltadas para ganhos instrumentais ou reivindicações negociáveis; sua ênfase, entretanto, é a defesa de bens coletivos "não-negociáveis" (por exemplo, igualdade de gênero e racial; defesa do meioambiente, paz etc).

Ao consagrar a participação popular na gestão da coisa pública, a Constituição Federal de 1988 priorizou a última modalidade, princípio que foi reiterado pela Constituição de Minas Gerais de 1989 e por diversas Leis Orgânicas municipais, que prevêem a criação de Conselhos temáticos estaduais e municipais, relacionados a questões relevantes para os cidadãos, tais como educação, saúde, habitação, assistência social, entre outras.

É interessante ressaltar que já no período autoritário verifica-se a iniciativa de organização de Conselhos Estaduais Setoriais. A consulta à legislação produzida em Minas Gerais, nos anos 70 e 80, aponta a criação de diversos Conselhos, tais como: Cultura (Decreto 17740 de 1976), Educação (Decreto 19275 de 1978), Desenvolvimento Urbano (Decreto 19946 de 1979), Política Habitacional (Decreto 22516 de 1982) e Mulher (Decreto 22971 de 1983). Não obstante, algumas importantes características distinguem esses Conselhos daqueles organizados a partir das Constituições Federal (1988) e Estadual (1989).

Em primeiro lugar, vale sublinhar as diferenças relativas à iniciativa legal de

${ }^{3}$ Idem. 
implantação dos Conselhos. Aqueles vigentes sob o autoritarismo foram criados por iniciativa do Poder Executivo, consubstanciada em decretos de autoria do Governador do Estado. No período atual, eles são previstos nos textos constitucionais e criados por meio de projetos de leis discutidos e aprovados no Poder Legislativo.

Em segundo lugar, são distintas as atribuições desses dois grupos de Conselhos. Os existentes sob o regime militar eram, em geral, consultivos e propositivos. Apenas em alguns casos dispunham de poder fiscalizador e regulador em relação às políticas previamente definidas pelo Estado para cada setor. Atualmente, eles possuem, em sua maioria, caráter deliberativo e fiscalizador das políticas públicas às quais estão afetos.

Finalmente, a diferença mais importante a ser destacada refere-se à sua composição e à forma de seleção de seus membros. Sob o regime autoritário, os membros dos Conselhos Setoriais eram designados pelo governador, a partir de sua livre escolha, ou indicados pelos titulares dos órgãos públicos nos quais estavam lotados. ${ }^{4} \mathrm{~A}$ única exceção constatada até o momento ${ }^{5}$ diz respeito aos representantes dos setores empresariais (indústria, comércio e agricultura), que eram indicados pelas respectivas entidades classistas. Assim, no Conselho Estadual de Ciência e Tecnologia, criado em 1982, tinham assento, além dos membros vinculados a diversos órgãos públicos, representantes da Federação das Indústrias do Estado de Minas Gerais (FIEMG) e da Federação da Agricultura do Estado de Minas Gerais (FAEMG), indicados pelas respectivas entidades.

Em contrapartida, os Conselhos hoje existentes são, na maior parte, paritários ou com predominância numérica de membros originários de entidades da sociedade civil e escolhidos por seus pares, configurando uma relação de representação mais democrática. A título de exemplo, vale citar a lei estadual 13176 de janeiro de 1999, que cria o Conselho Estadual do Idoso, “órgão deliberativo e controlador das políticas e das ações voltadas para o idoso no âmbito do Estado (...)", de composição paritária entre o poder público e a sociedade civil. No plano federal, pode-se constatar ênfase semelhante, como expressa no artigo 194 da Constituição brasileira, relativo à Seguridade Social, que garante o "caráter democrático e descentralizado da administração, mediante gestão quadripartite, com participação

\footnotetext{
${ }^{4}$ Exemplo do primeiro caso é o Decreto 19946, de 1979, que criou o Conselho Estadual de Desenvolvimento Urbano (CEDUR) e que dispôs sobre sua composição: Secretário de Estado do Planejamento e Coordenação Geral (presidente); Secretários Adjuntos do Planejamento e Coordenação Geral, da Fazenda, de Obras Públicas, e de Indústria, Comércio e Turismo; e 8 (oito) membros designados pelo Governador do Estado, com mandato de 2 (dois) anos. Já o Conselho Estadual de Política Habitacional, instituído em 1982, também por decreto de autoria do Executivo, era presidido pelo Secretário de Estado de Obras Públicas e integrado exclusivamente por representantes de órgãos estatais indicados pelos respectivos titulares e nomeados pelo Governador do Estado.

${ }^{5}$ É muito extensa a legislação referente aos Conselhos Setoriais, da década de sessenta até os dias atuais. A pesquisa a esses documentos ainda encontra-se em curso.
} 
dos trabalhadores, dos empregadores, dos aposentados e do Governo nos órgãos colegiados" 6 .

Essas iniciativas têm se consubstanciado em novos mecanismos institucionais de participação, implantados nos três níveis da Federação desde o início da década de noventa. As experiências brasileiras de participação ampliada - ainda que minoritárias frente às iniciativas de participação restrita — têm crescido significativamente na última década.

Em consonância com os dispositivos consagrados pelas Constituições Federal (1988) e Estadual (1989), a Lei Orgânica de Belo Horizonte incorpora o princípio da participação popular e prevê a organização dos Conselhos Setoriais.

Entre os cerca de 25 municípios que compõem a Região Metropolitana de Belo Horizonte (RMBH) foram detectados, no final da última década, 125 Conselhos Setoriais ${ }^{7}$, incluindo os já existentes e aqueles em fase de implantação. Ressalte-se que apenas $8 \%$ destes foram criados até 1989 , tendo sido os demais $(92 \%)$ implantados nos anos noventa.

Situação similar pode ser observada na Região Metropolitana do Rio de Janeiro (RMRJ), onde apenas dois dos 75 Conselhos analisados foram instalados antes de 1988, 34 foram criados entre 1989/1996 e os 39 restantes foram implantados em 1997/98 (SANTOS, M.R.M., 2000:58).

Em suma, os dados mostram que os Conselhos Setoriais constituem fenômenos recentes, que expressam importante inovação institucional no âmbito dessas duas grandes metrópoles.

$\mathrm{Na}$ Região Metropolitana de Belo Horizonte, os Conselhos mais difundidos são os de Saúde (dezenove), seguidos pelos do Meio Ambiente (dezessete), da Assistência Social (dezesseis) e da Criança e do Adolescente (dezesseis). Posteriormente, com incidência bem menor, aparecem os Conselhos de Alimentação Escolar (dez), Educação (sete), Mulher (seis), Transporte (cinco) e Habitação (quatro).

Também aqui ocorre importante semelhança com a RMRJ, onde os Conselhos mais difundidos são os de Saúde (quatorze), seguidos pelos da Criança e do Adolescente (doze), da Educação (onze) e da Assistência Social (dez) (Santos, M.R.M., 2000:58).

Vale ressaltar que os Conselhos que apresentam maior incidência entre os municípios das duas Regiões são aqueles exigidos pela legislação federal, excetuandose os Conselhos de Educação na RMBH (sete) e os Conselhos de Meio Ambiente na RMRJ (dois).

Embora não tenha sido possível averiguar o desempenho qualitativo dos dife-

\footnotetext{
${ }^{6}$ Ver, a respeito: Anastasia, Avritzer \& Eisenberg: Inovações Institucionais e a Participação Política: a Democracia em Belo Horizonte (Projeto de Pesquisa apresentado ao Programa de Doutorado em Ciências Humanas: Sociologia e Política), Belo Horizonte, junho de 2000.

${ }^{7}$ A maioria dos dados referentes aos Conselhos Setoriais da RMBH são oriundos de pesquisas realizadas pelo Centro de Estudos Urbanos da Universidade Federal de Minas Gerais (CEURB, 1998).
} 
rentes Conselhos, foi surpreendente constatar que apenas onze (9\%) dos 125 Conselhos levantados na RMBH foram considerados inoperantes pelos entrevistados.

Em suma, cerca de $90 \%$ do Conselhos encontravam-se em operação, no momento da pesquisa, ainda que em diferentes estágios de funcionamento.

No que diz respeito à composição dos Conselhos mais diretamente vinculados à questão urbana - Desenvolvimento Urbano, Habitação, Meio Ambiente, Saneamento, Transporte, entre outros - pode-se constatar que do total de 26 Conselhos da RMBH, 39\% têm composição paritária de representantes da sociedade civil e de agências governamentais; $42 \%$ possuem maioria da sociedade civil e apenas $19 \%$ possuem predominância de representantes governamentais ${ }^{8}$. Da mesma forma, na RMRJ "na maioria das vezes, os Conselhos têm composição paritária entre Estado e Sociedade [...] e possuem caráter deliberativo" (Santos, 2000, M.R.M.: 114).

Os dados disponíveis sobre o perfil dos Conselheiros na RMRJ mostram que os mesmos possuem nível educacional, de renda, de filiação partidária e de informação muito acima da média da população, independentemente do tamanho do município e do partido no governo. Ademais, a maioria dos representantes de grupos organizados da sociedade participa dos Conselhos em caráter voluntário (Santos, M.R.M., 2000; Santos Junior, 2001). No caso da RMBH, apesar de as informações estarem menos sistematizadas, tanto as pesquisas já realizadas (Avritzer, 1998), como os dados preliminares levantado sobre o padrão associativo vigente (OPUR, 2001), apontam para um perfil similar àquele dos conselheiros da Região Metropolitana do Rio de Janeiro. Vale, ainda, frisar que análises setoriais de diferentes Conselhos, realizadas na RMBH, também caminham nessa direção (Santos, M. R. M., 2000; OPUR, 2001).

Muitos participantes dos Conselhos da RMRJ avaliam-nos como instrumentos que propiciam significativo avanço democrático, tanto no que se refere aos procedimentos de escolha de seus membros quanto no que diz respeito ao "poder de agenda" conferido aos diferentes atores envolvidos (Santos, M.R.M., 2000:78; Santos Junior, 2001:220-222).

Em relação à RMBH, em que pese a menor disponibilidade de informações, os levantamentos preliminares já realizados permitem inferir que a maioria dos Conselheiros avalia como positiva a experiência dos Conselhos, ainda que alguns considerem que vários deles foram criados por exigência dos órgãos federais ou estaduais, como condição para a liberação de verbas para o setor, e não por iniciativa dos próprios cidadãos (CEURB, 1997; Fundação João Pinheiro, 1999; OPUR, 2001).

\footnotetext{
${ }^{8}$ Entre os que apresentam maioria governamental cabe destacar o Conselho Deliberativo do Patrimônio Cultural do Município "composto por 17 titulares, sendo quatro representantes da administração pública; dois representantes da Câmara Municipal; dois representantes das entidades estatais ligadas à defesa do patrimônio histórico; quatro representantes da sociedade civil; um representante do SINDUSCON; três membros adicionais indicados pelo Prefeito, e, ainda, o Procurador Geral do Estado. O Conselho é deliberativo e pode efetuar tombamentos" (Avritzer: 2000a:17).
} 


\section{ORÇAMENTO PARTICIPATIVO EM BELO HORIZONTE: A IMPORTÂNCIA ESTRATÉGICA DA QUESTÃO INSTITUCIONAL}

A política de Orçamento Participativo ganhou visibilidade nacional a partir dos anos oitenta com a experiência exitosa de Porto Alegre (1999) e logo se espalhou para diversas capitais, atingindo tanto as chamadas administrações populares, capitaneadas pelo Partido dos Trabalhadores - Belo Horizonte9 ${ }^{9}$, Vitória, Brasília, Belém ${ }^{10}$ - quanto grandes metrópoles governadas por outros partidos de diferentes tendências (Salvador, Recife) ${ }^{11}$. Atualmente, dezenas de cidades pequenas e médias do país implementam programas similares, utilizando diferentes formatos institucionais ${ }^{12}$.

No caso de Belo Horizonte, há de ser realçada a centralidade da Secretaria Municipal de Planejamento, que conta com pessoal qualificado e é detentora de grande força política e do controle de importantes "recursos críticos", de natureza orçamentária. O reaparelhamento da Secretaria de Planejamento, a sintonia fina com a Secretaria Municipal da Fazenda e a descentralização das Regiões Administrativas foram elementos cruciais para o bom desempenho do OP.

$\mathrm{Na}$ verdade, na área urbana, criou-se um engenhoso e eficaz sistema de planejamento, buscando recuperar uma visão compreensiva para questões consideradas estratégicas pelo poder público, concentrando esforços na superação de pontos críticos $^{13}$.

A Prefeitura instituiu um colegiado de coordenação, que envolve todos os órgãos e Secretarias Municipais de vocação urbana, denominado Comissão Munici-

\footnotetext{
9 “No âmbito institucional, Belo Horizonte, terceiro maior contingente populacional do país, implementou, nas gestões do Partido dos Trabalhadores (PT), entre 1993/1996, e do Partido Socialista Brasileiro (PSB), entre 1997/2000, o Orçamento Participativo (de agora em diante OP). Concebido para atender as reivindicações da população e permitir um maior controle sobre as finanças públicas municipais, com a definição detalhada dos empreendimentos, sua inovação consiste, basicamente, na realização de plenárias regionais anuais - bianuais, a partir de 2000 - , com a participação da população e de entidades da sociedade civil organizadas, para discutir suas demandas e eleger delegados para os fóruns de deliberação regionais.” (Anastasia, Avritzer \& Eisenberg, 2000)

${ }^{10}$ Para um balanço de algumas dessas experiências ver, entre outros, Carvalho \& Miller, 1998; Santos, M. R. S, 1996; Faria, 1996; Somarriba \& Dulci, 1996; Boschi,1999; Avritzer, 1998.

11 Ainda que Porto Alegre se apresente como o grande impulsionador da idéia do Orçamento Participativo, estudos recente indicam que Olívio Dutra, primeiro Prefeito do Partido dos Trabalhadores a implantar esse projeto naquela cidade, teria se inspirado em programa análogo denominado "A Prefeitura nos Bairros" desenvolvido na primeira administração de Jarbas de Vasconcelos, na cidade de Recife, no início da década de oitenta. Ver a respeito Melo, 2000.

12 Vale lembrar, ainda, que Minas Gerais foi um estado pioneiro ao prever e disciplinar, no texto constitucional, a realização das Audiências Públicas para discussão orçamentária, inicialmente no plano regional e posteriormente também no plano municipal. Diferentemente do chamado Orçamento Participativo, capitaneado pelas prefeituras municipais, as Audiências Públicas foram iniciativa do Poder Legislativo e têm abrangência estadual.

${ }^{13}$ A recente literatura latino-americana sobre o tema denomina esse enfoque como sendo de Planejamento “estratégico", “adaptativo" ou, ainda, "situacional” (Cintra, 1978; Matus, 1993; Azevedo, 1994).
} 
pal de Política Urbana - COMPUR. Essa nova postura de planejamento pressupõe a heterogeneidade da máquina pública, respeitando os diversos paradigmas das diferentes burocracias e tentando compatibilizar metas, por meio de negociações. As atividades de coordenação concentraram-se nas fronteiras e interfaces dos órgãos e políticas governamentais.

Assim, antes de abrir a discussão com os setores organizados da sociedade, logrou-se pactuar, na Prefeitura, uma proposta consensual de OP.

No referente à democratização da relação entre o Estado e a sociedade, a experiência do OP em Belo Horizonte aumentou a visibilidade e a transparência do processo orçamentário, anteriormente visto apenas como questão que dizia respeito a um pequeno número de especialistas. Em segundo lugar, atingiu frontalmente as práticas clientelistas de alocação de recursos. Ao instituir uma arena pública para a negociação de interesses, envolvendo associações reivindicativas, movimentos sociais e indivíduos, o OP integra amplos setores no processo de tomada de decisão sobre a alocação de recursos da Prefeitura - o que é um ganho para o fortalecimento da cidadania - e rompe com os paradigmas clássicos da Administração Pública ${ }^{14}$.

Além disso, esse é um processo educativo que permite, a partir de demandas particularistas e por meio de um processo de filtragem e de negociações sucessivas, não só discutir questões mais amplas da cidade, como desenvolver políticas de solidariedade frente aos mais necessitados ${ }^{15}$.

Outra questão crucial diz respeito às transformações político-administrativas advindas do processo de mobilização da população. Do ponto de vista político é interessante notar que mesmo o legislativo municipal terminou por abrir mão de - ou pelo menos por reduzir consideravelmente - seu poder de veto no que se refere às prioridades definidas pelo OP. Vale, ainda, frisar o impacto modernizador do OP sobre as diferentes agências públicas municipais. Verifica-se um significativo consenso de que, em que pesem as iniciativas tradicionais de modernização (reformas administrativas, reformulação dos organogramas etc.), as transformações e o

14 “O OP de Belo Horizonte é dividido em: OP Regional, criado em 1993; OP Habitação, criado em 1995, e OP Cidade, criado em 1998. Os dois primeiros alocam recursos para a realização dos empreendimentos regionais e de habitação, respectivamente. A população de cada regional se organiza para definir onde os recursos vão ser aplicados, visando melhorias no seu bairro ou na sua região. Os empreendimentos são de infra-estrutura (pavimentação, contenção de encosta, drenagem etc.), de urbanização de vilas e favelas, de construção, reforma e ampliação de unidades de educação, saúde, praças, aquisição de terrenos e construção de moradias, dentre outros. O último integra a discussão das políticas sociais de educação, saúde, habitação, cultura, esporte e desenvolvimento visando a alocação dos recursos de todo o orçamento municipal, mediante controle público sobre as prioridades do Município.” (Anastasia, Avritzer \& Eisenberg, 2000: 8)

15 Os recursos destinados às obras do OP em Belo Horizonte são alocados da seguinte forma: “ $50 \%$ são divididos igualmente entre as nove regionais da cidade e $50 \%$ divididos a partir da classificação de cada regional no IQVU (Índice de Qualidade de Vida Urbana), um índice que envolve uma composição entre população e renda no município. Quanto maior é o IQVU da regional, menor é a quantidade de recursos a ela destinados pelo OP” (Anastasia, Avritzer \& Eisenberg, 2000: 8). 
aumento da eficiência desses órgãos devem ser, em grande parte, debitados à pressão e à maior capacidade de fiscalização dos cidadãos, propiciadas pelos instrumentos a eles disponibilizados pelo OP.

O maior mérito do OP é combinar as características democráticas e progressistas, acima mencionadas, com sua capacidade de competir vantajosamente com as práticas clientelistas tradicionais. Tanto é assim que mesmo políticos de tradição clientelista vêm percebendo, naquelas municipalidades onde o OP tem sido adotado regularmente, que se contrapor ou resistir a ele tem trazido expressivos custos políticos. Por outro lado, verificam-se tentativas, por parte dos políticos tradicionais, de "capturar" o OP, pois o "novo" sempre vem, em maior ou menor grau, misturado com o "velho". Os políticos de corte clientelista e grupos que possuem controle sobre algum tipo de recurso estratégico vão sempre tentar adaptar suas práticas aos novos procedimentos do OP, os quais, por sua vez, têm sido objeto de aprimoramento institucional ${ }^{16}$.

Em termos de constrangimentos deve-se ressaltar que o OP enfrenta o chamado engessamento dos gastos orçamentários, o que diminui consideravelmente as margens de manobra e de alocação de recursos do Poder Executivo nos três níveis de governo. Pode-se dizer que, devido a dotações previamente definidas em lei e a despesas de custeio da máquina pública municipal, na verdade não sobram muitos recursos cuja alocação possa ser decidida por meio do OP. No caso de Belo Horizonte, o percentual e as verbas disponíveis foram relativamente baixos para o porte da cidade, especialmente no primeiro ano de sua implementação, não passando de $5 \%{ }^{17}$ da receita orçamentária anual total.

Embora se reconheça que a efetividade de uma política desse tipo possa ficar comprometida se os recursos envolvidos no programa se situarem em um patamar modesto, é necessário matizar essa questão. Em primeiro lugar, devido ao relativo sucesso dessas políticas - em cidades como Belo Horizonte e Porto Alegre - têmse manifestado crescentes pressões para a alocação de mais verbas para o OP. Em segundo lugar, os ganhos dessa prática ultrapassam em muito o simples acesso a bens públicos de primeiro nível, considerados prioritários pela população da cida-

\footnotetext{
${ }^{16}$ Vale sublinhar, no entanto, que não foram produzidos ainda na RMBH, salvo melhor juízo, resultados de pesquisa sistematizados sobre as formas de interação entre as "instituições híbridas" e os instrumentos de participação política preexistentes (partidos, sindicatos, associações civis). Assim, não é possível, no momento, aferir e analisar os impactos e os efeitos produzidos pelas novas formas de participação sobre aquelas tradicionais e vice-versa. Projetos, em andamento, tanto na Universidade Federal de Minas Gerais (Anastasia, Avritzer \& Eisenberg, 2000 op. cit), como na Pontifícia Universidade Católica de Minas Gerais, por meio do Observatório de Políticas Urbanas da RMBH (OPUR: 2001) buscam, entre outros objetivos, aprofundar a análise dessas relações. No caso da RMRJ os dados disponíveis mostram que "enquanto a filiação partidária atinge apenas $2 \%$ da população adulta metropolitana, quase a metade, ou precisamente $44 \%$ dos conselheiros da sociedade civil está filiada a partidos políticos. Esse elevado percentual independe do município ou do segmento social representado" (Santos Junior, 2001: 217).

17 Com a mobilização de aproximadamente 200 mil pessoas desde 1993, foram aprovados 719 empreendimentos, dos quais $70 \%$ já estão concluídos, incluindo a alocação de 34 milhões de reais (aproximadamente 20 milhões de dólares) em recursos aprovados para o OP Habitação (Avritzer, 2000).
} 
de. A dinâmica do OP possui grande potencialidade educativa, significando ganhos em várias dimensões da cidadania. Cresce o número de pessoas envolvidas com a questão do orçamento e, ademais, altera-se a natureza de sua interação com os poderes públicos, aumentando os graus de accountability e de responsiveness da ordem política.

No que se refere aos padrões de participação política, tomados como expressões de competição e de cooperação entre os diferentes atores individuais ou coletivos, ocorre um aprendizado da política enquanto arena de alianças, negociação, conflitos e barganhas. Os atores iniciam o processo com uma visão micro (a casa, a rua e no máximo o bairro) e uma pauta maximalista (demandando todas as necessidades básicas) e, paulatinamente, com o desenrolar do processo, aproximamse de uma visão mais compreensiva da cidade, dos problemas urbanos e das limitações governamentais, passando a defender uma pauta mais realista.

Isso significa dizer que a política deixa de ser vista, e experimentada, apenas como um processo de agregação de preferências dadas e passa a incorporar uma dimensão deliberativa, que envolve também a formação e a transformação das preferências, a construção do consenso e a explicitação do dissenso e da diferença.

\section{REPRESENTAÇÃO E PARTICIPAÇÃO: A DEMOCRACIA COMO UM JOGO EM "MÚLTIPLAS ARENAS"18}

Passaremos a analisar, a seguir, os Seminários Legislativos implementados pela Assembléia Legislativa de Minas Gerais (ALEMG), os quais constituem interessante inovação institucional na medida em que permitem o exercício da cidadania democrática nos interstícios eleitorais e na arena parlamentar.

Um dos principais problemas teóricos e práticos da democracia refere-se às relações, em geral tensas, entre o plano da participação e o plano da representação políticas. Os cidadãos, enquanto principals, delegam aos representantes, seus agents, através do processo eleitoral, autoridade para agirem em seu nome ou em seu interesse, mas dispõem de poucos instrumentos de sinalização de suas preferências, bem como de fiscalização das ações dos governantes. Ainda que as eleições, além de constituírem mecanismos de seleção, possuam também uma função controladora, já que os principals podem reeleger ou punir seus agentes, o caráter retrospectivo do controle exercido por meio do processo eleitoral limita sua eficácia no período entre as eleições.

Os Seminários Legislativos são eventos institucionalizados, que contam com a participação de entidades civis e governamentais. Nesses eventos são debatidos

\footnotetext{
${ }^{18}$ Esta seção é uma versão resumida de parte do paper intitulado "Transformando o Legislativo. A experiência da Assembléia Legislativa de Minas Gerais”(Anastasia, 1998), apresentado no $1^{\circ}$ Encontro da Associação Brasileira de Ciência Política (ABCP), realizado em dezembro de 1998.
} 
temas relevantes para a população do Estado e são apresentadas propostas de legislação que servem de subsídios à atividade parlamentar.

A iniciativa de organização dos Seminários resultou da percepção de que a participação popular poderia conferir maior legitimidade às ações legislativas, e foi informada pela experiência, desenvolvida durante os trabalhos constituintes, "de mobilização da sociedade, por meio das comissões temáticas, para subsidiar os parlamentares mineiros na elaboração da Constituição de $1989^{19}$ ".

Implantados a partir de 1991, os Seminários Legislativos encontram-se, hoje, plenamente institucionalizados e são realizados de acordo com um conjunto de procedimentos devidamente normatizados, descritos no Quadro I.

As competências das entidades participantes e dos setores da Assembléia vinculados à realização dos Seminários são definidas por deliberações da Mesa. Vale ressaltar a figura da Comissão de Representação, constituída a partir das indicações feitas pelas entidades participantes e responsável pela supervisão de todo o processo e, especialmente, pelo acompanhamento e avaliação da implementação institucional das propostas contidas no documento final.

Destacam-se, como atores relevantes desse processo, além das entidades participantes que constituem o público-alvo dos Seminários - "entidades patronais e de trabalhadores, de movimentos sociais, instituições acadêmicas, órgãos públicos, organizações não-governamentais, que tenham envolvimento com o tema proposto ${ }^{20}$ " - a própria Mesa da Assembléia, enquanto comissão executiva responsável pela direção dos trabalhos legislativos, o Comitê Deliberativo de Comunicação Institucional, ao qual foram atribuídas as atividades de coordenação política dos Seminários, e as Comissões permanentes da Assembléia.

Por meio dos Seminários Legislativos, novos atores e novos issues foram introduzidos no processo parlamentar, facultando aos setores organizados da população vocalizar suas preferências e informar os deputados sobre suas prioridades em relação a cada uma das questões em pauta.

A própria dinâmica da interação propiciada por tais eventos merece atenção: na medida em que esses novos loci institucionais promovem a interação direta, não apenas dos grupos organizados com os parlamentares mas, também, desses grupos uns com os outros, importantes conseqüências vão emergir, no que respeita à organização, ao processo e à produção legislativa.

No plano da organização legislativa, vale mencionar que antes da introdução desses eventos prevalecia um formato institucional no qual a relação com a sociedade, quando acontecia, se dava por meio dos gabinetes dos deputados. Decorre daí que cada deputado só tinha como auscultar seu próprio eleitorado ou "clientela". Essa demanda caracterizava-se, também, em sua maior parte, por ser individualizada, de caráter particularista, por benefícios de natureza fisiológica e clientelista.

As novas formas de interlocução com a sociedade propiciaram maior interação

\footnotetext{
19 “Seminários Legislativos. Questionário para o Programa Gestão Pública e Cidadania.” ALEMG, 1996: 4.

20 “Seminários Legislativos. Questionário para o Programa Gestão Pública e Cidadania”, op. cit.: 2.
} 


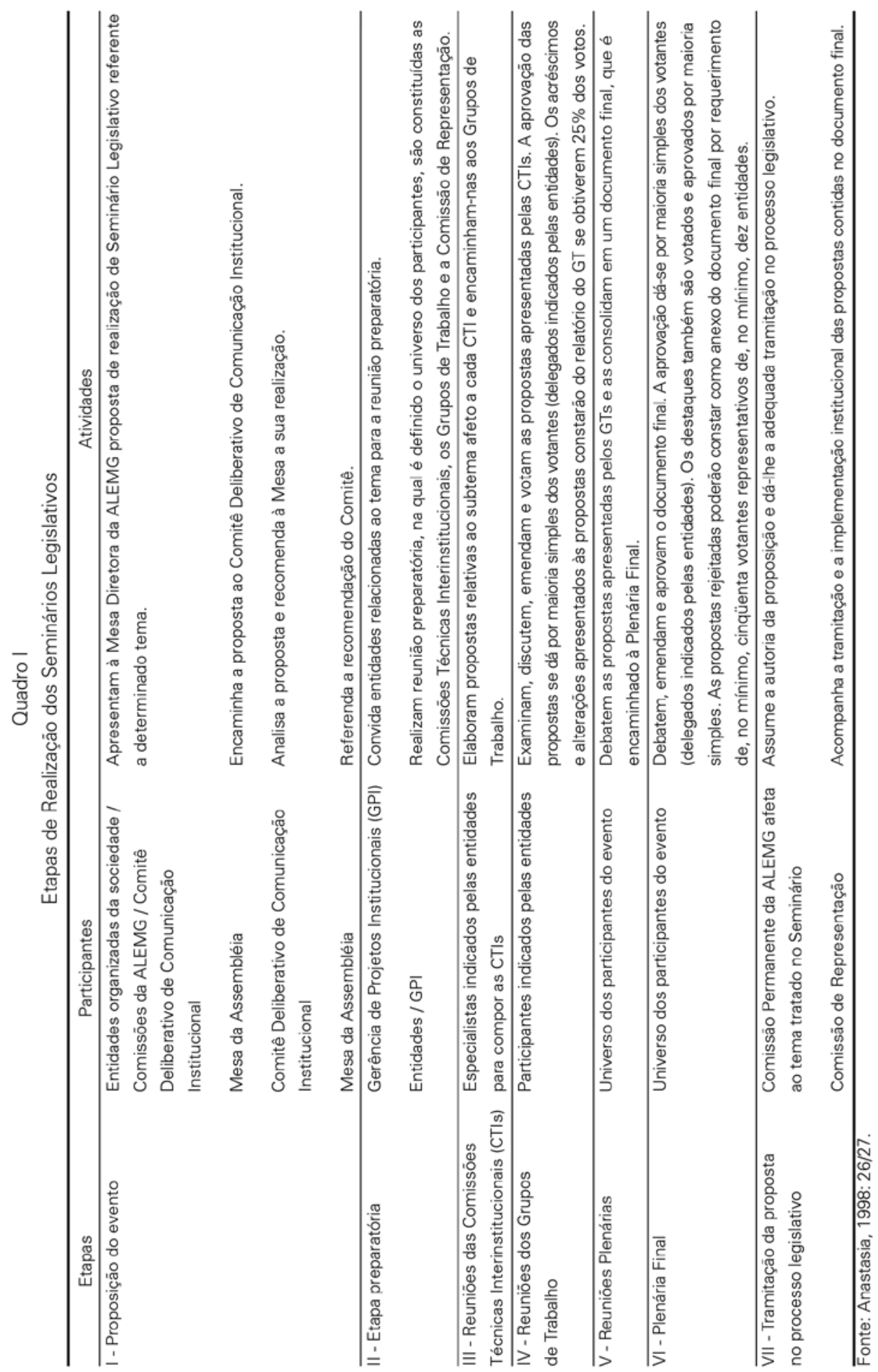


dos legisladores com uma multiplicidade de atores coletivos, altamente interessados nos issues em discussão e portadores de diferentes orientações políticas e ideológicas em relação a essas questões. Dessa forma, cada deputado individualmente e o conjunto da legislatura passaram a estar expostos a uma pluralidade de interesses, de demandas e de preferências que lhes permite ter uma visão muito mais compreensiva dos temas em pauta nesses eventos.

Por outro lado, a interação dos grupos organizados entre si e o caráter propositivo conferido aos Seminários remete para o desafio da construção de algum consenso sobre os encaminhamentos que deles deverão resultar.

Os novo loci institucionais permitem, em adição, a explicitação e o tratamento dos pontos de dissenso existentes entre os diversos atores coletivos e a organização do consenso possível, o qual vai informar as propostas de legislação que são encaminhadas, ao final de cada evento, para as comissões pertinentes.

No Quadro II encontram-se sintetizadas informações sobre os Seminários Legislativos realizados entre 1991 e 2000. Desses eventos resultaram propostas de legislação, algumas das quais encontram-se em tramitação na Casa e outras já foram transformadas em leis: Política Estadual de desenvolvimento Agrícola (Lei ${ }^{\circ}$ 11.405, de 28/1/94); Política Estadual de Recursos Hídricos (Lei no 11.504, de 20/ 6/94); Política Estadual de Saneamento Básico (Lei no 11.720, de 29/12/94); Fundo Estadual de Saneamento Básico (Lei n ${ }^{\circ} 11.719$, de 28/12/94); Fundo Estadual de Desenvolvimento Rural — FUNDERUR (Lei n ${ }^{\circ} 11.744$, de 16/1/95); Fundo Estadual de Habitação (Lei $n^{\circ} 11.830$, de 6/7/95); Plano Mineiro de Turismo (Lei ${ }^{\circ}$ 12.398, de 12/12/96); Fundo de Assistência ao Turismo - FASTUR (Lei ${ }^{\circ}{ }^{\circ} 11.520$ )

A partir de 1999, por decisão da Mesa da Assembléia, os Seminários Legislativos foram interiorizados, passando a ser realizados em diversos municípios de Minas Gerais, com o objetivo de coletar propostas para serem posteriormente discutidas em eventos de amplitude estadual, realizados na sede da Assembléia Legislativa, em Belo Horizonte. Assim, no período compreendido entre 19 de agosto e 21 de setembro de 1999, foram realizadas discussões em dez municípios mineiros ${ }^{21}$, sobre "Desemprego e Direito ao Trabalho", seguidas do Seminário Legislativo ocorrido em Belo Horizonte, entre 27 e 30 de setembro do mesmo ano. Iniciativa similar foi tomada em relação ao tema educacional. O Seminário Legislativo "Construindo a Política e Educação Pública em Minas Gerais”, realizado na ALEMG entre 18 e 21 de outubro de 1999, foi precedido de eventos em dez municípios ${ }^{22}$, com vistas a

\footnotetext{
${ }^{21}$ Foram realizados Seminários Legislativos nos seguintes municípios: Paracatu; Montes Claros; Juiz de Fora; Teófilo Otoni; Ipatinga; Divinópolis; Uberlândia; Patos de Minas; Varginha e Belo Horizonte (Fonte: Área de Projetos Institucionais da ALEMG, 2000).

22 Os seguinte municípios realizaram Seminários Legislativos sobre o tema educacional: Montes Claros; Ipatinga; Divinópolis; Uberlândia; Patos de Minas; Varginha; Teófilo Otoni; Paracatu; Juiz de Fora e Belo Horizonte (Fonte: Área de Projetos Institucionais da ALEMG, 2000).
} 
"discutir com as entidades da sociedade civil, no interior do Estado, propostas relativas e ao tema" 23 , e colher subsídios para posterior discussão em Belo Horizonte.

\begin{tabular}{lccc}
\multicolumn{4}{c}{ Quadro II: Seminários Legislativos (1991-1998) } \\
\hline Nome/Tema & Data & $\begin{array}{c}\text { Número de } \\
\text { Participantes }\end{array}$ & $\begin{array}{c}\text { Número de } \\
\text { Entidades }\end{array}$ \\
\hline Educação: A Hora da Chamada & Outubro / 1991 & 883 & 11 \\
Minas Terra: Políticas Agrícola e Agrária & Abril / 1992 & 461 & 24 \\
Saneamento É Básico & Junho / 1992 & 672 & 35 \\
Águas de Minas & Outubro / 1993 & 652 & 53 \\
Moradia: Alicerce da Cidadania & Setembro / 1995 & 774 & 33 \\
Turismo: Caminha das Minas & Outubro / 1995 & 652 & 47 \\
Reforma Agrária & Setembro / 1996 & - & - \\
Direitos Humanos e Cidadania & Agosto / 1998 & - & - \\
\hline
\end{tabular}

Fonte: Anastasia, 1998: 29.

\section{CONCLUSÕES}

As relações entre demandas, políticas e resultados constituem uma cadeia causal (Arnold, 1990) cuja traceabilidade depende, entre outros fatores, do desenho conferido às instituições políticas por meio das quais as preferências dos cidadãos são vocalizadas e admitidas na agenda pública, informando a formulação sobre as políticas públicas e a sua implementação.

Nas democracias, os cidadãos dispõem de mais de um agente (Arnold, 1990; Manin, Przeworski e Strokes, 2000), já que à(s) oposição(ões) interessa fiscalizar os atos e as omissões dos governantes. Não obstante, dado o controle diferencial de recursos políticos existente nas sociedades contemporâneas, especialmente naquelas atravessadas por altos graus de desigualdades econômicas e sociais, alguns atores individuais e/ou coletivos terão maiores oportunidades e condições de expressar suas preferências e de inseri-las na agenda pública do que outros.

Se o voto universal e secreto, baseado no princípio de igualdade política, constitui um recurso mobilizado pelas democracias para anular, ou minorar, os efeitos do sistema de desigualdades sobre o sistema político (Pizzorno, 1966), a invenção e a institucionalização dos instrumentos de ação coletiva - partidos, sindicatos, associações - , foram responsáveis, segundo Pizzorno, pela reintrodução do privado na política. O que significa dizer que, mesmo nas democracias, o poder de

${ }^{23}$ Fonte: Área de Projetos Institucionais da ALEMG, 2000. 
agenda ${ }^{24}$ dos diferentes atores políticos é uma variável dependente das condições sociais e institucionais vigentes em cada sociedade. Assim, paralelamente aos instrumentos formais da democracia representativa, estão surgindo novos mecanismos de responsabilização, que enfatizam a participação dos cidadãos no processo de tomada de decisão das políticas públicas, ou seja a construção de arenas públicas onde as chamadas instituições híbridas podem viabilizar "a participação dos cidadãos ou o controle social dos serviços públicos e, mais amplamente, do Estado [...]. Elas são dotadas de diferentes graus de formalização, mas nas democracias contemporâneas, especialmente no nível local, elas vêm adquirindo uma importância crescente." (Bresser-Pereira; 1998: 145-6).

Além disso, novos formatos institucionais podem ser pensados e operacionalizados com vistas a diminuir a assimetria de recursos entre os atores, com ênfase nos recursos de informação, cuja concentração, como se sabe, perturba, distorce e, no limite, inviabiliza o processo democrático.

Consideramos que a inovação propiciada pelas denominadas instituições híbridas constitui, ao menos potencialmente, interessante solução institucional, que pode produzir impactos equalizadores sobre o padrão de distribuição de recursos políticos, inserindo na agenda pública novos atores, novos issues, novos procedimentos de responsividade, e afetando, conseqüentemente, tanto a natureza das decisões quanto as políticas públicas e os seus resultados.

\section{REFERÊNCIAS BIBLIOGRÁFICAS}

ANASTASIA, F.; AVRITZER, L. \& EISENBERG, J. Inovações Institucionais e a Participação Política: a Democracia em Belo Horizonte (Projeto de Pesquisa apresentado ao Programa de Doutorado em Ciências Humanas: Sociologia e Política), Belo Horizonte, junho de 2000.

ANASTASIA, Fátima, "Transformando o Legislativo. A experiência da Assembléia Legislativa de Minas Gerais”, paper apresentado no $1^{\circ}$ Encontro da Associação Brasileira de Ciência Política (ABCP), realizado em dezembro de 1998.

ANASTASIA, Fátima, “A Responsabilização por Controle Parlamentar” In: A Responsabilização da Administração Pública na América Latina, Venezuela, CLAD, 2000.

ARNOLD, R. Douglas. The Logic of Congressional Action. New Haven, Yale University Press, 1990.

AVRITZER, Leonardo. Cultura Política, Associativismo e Democratização: uma análise do associativismo no Brasil. DCP/FAFICH/UFMG, Mimeo, 1998.

AVRITZER, Leonardo. Sociedade Civil, Espaço Público e Poder Local: Uma Análise do Orçamento Participativo em Belo Horizonte e Porto Alegre. Relatório Final do Projeto Civil Society and Governance. DCP/FAFICH/UFMG, Mimeo, 2000.

\footnotetext{
24 "Por poder de agenda entendemos a capacidade de iniciativa política, entendida enquanto capacidade de inserir na agenda política alternativas que correspondam às preferências e/ou aos interesses dos atores. Essa capacidade engloba o direito de formular e de expressar preferências [...], o direito de 'ter suas preferências igualmente consideradas na conduta do governo' (Dahl, 1997:26), o direito de propor, iniciar ou modificar legislação, o direito de determinar ritmos e sequiências de procedimentos ao longo do processo decisório (Figueiredo e Limongi, 1999: 69), a atribuição de execução de políticas públicas e o direito de fiscalização da conduta dos agentes.” (Anastasia, 2000:5)
} 
AVRITZER, Leonardo. Esfera Pública, Teoria Democrática e Participação; Uma Análise da Deliberação nos Conselhos de Políticas. DCP/FAFICH/UFMG, Mimeo, 2000a.

AZEVEDO, Sergio de \& PRATES, Antonio Augusto. "Planejamento Participativo, Movimentos Sociais e Ação Coletiva”. In: Ciências Sociais Hoje. São Paulo, ANPOCS/ Vértice, 1991.

AZEVEDO, Sergio de. "Planejamento, Cidades e Democracia”. In: DINIZ, Eli \& LOPES, José S. L. \& PRADI, Reginaldo (Orgs). O Brasil no Rastro da Crise. S.Paulo, ANPOCS/IPEA/HUCITEC, 1994.

BOSCHI, Renato. "Governança, Participação e Eficiência das Políticas Públicas: exame de experiências municipais no Brasil”. In: MELO, André Marcus (Org). Reforma do Estado e Mudança Institucional no Brasil. Recife: Fundação Joaquim Nabuco, 1999.

BRESSER-PEREIRA, Luiz Carlos. Reforma do Estado para a Cidadania: a reforma gerencial brasileira na perspectiva internacional. Brasília, ENAP / Editora 34, 1998.

CARVALHO, Alice Kalyvas de \& MILLER, Laurie Jeanette. "Orçamento Participativo: a experiência do Distrito Federal”. In: Proposta. Rio de Janeiro, FASE, no. 78, 1991.

CEURB, Centro de Estudos Urbanos. Participação, Cidadania e Governança em Belo Horizonte. Convênio CEURB(UFMG) / GURI e IUPERJ, Belo Horizonte, 1997.

CINTRA, Antônio Octávio. "Planejando as cidades: política ou não política". In: CINTRA, Antônio Octávio \& HADDAD, Paulo Roberto (orgs.) Dilemas do Planejamento Urbano e Regional. Rio de Janeiro, Zahar Editores, 1978.

COELHO, Magda \& DINIZ, Eli. Governabilidade, Governança Local e Pobreza no Brasil. Rio de Janeiro, IUPERJ, 1995.

CONSTITUIÇÃO DA REPÚBLICA FEDERATIVA DO BRASIL ([1988]: 2000).

DAHL, R. Democracy and its Critics. New Haven, The Yale University Press, 1982.

DAHL, R. Poliarquia: Participação e Oposição. São Paulo, Editora da Universidade de São Paulo, 1997. DINIZ, Eli. "Governabilidade, governance e reforma do Estado: considerações sobre o novo paradigma”. Revista do Serviço Público. Ano 47, V. 120, No 2, Brasília, Mai-Ago 1996.

FARIA, Cláudia Feres. Democratizando a Relação entre o Poder Público Municipal e a Sociedade Civil: o orçamento participativo em Belo Horizonte. Belo Horizonte, UFMG/ Departamento de Ciência Política-DCP, 2000b (Tese, Mestrado Ciência Política).

FEDOZZI, Luciano. Orçamento Participativo: reflexões sobre a experiência de Porto Alegre, 2 ed. Rio de Janeiro, TOMO/UFRJ/IPPUR/FASE, 1999.

FEREJOHN, John. Accountability and Authority: Toward a Theory of Political Accountability. mimeog., NYU, 1997.

FIGUEIREDO, Argelina Cheibub \& LIMONGI, Fernando. Executivo e Legislativo na Nova Ordem Constitucional. Rio de Janeiro, Editora FGV, 1999.

FUNDAÇÃO JOÃO PINHEIRO. "Gestão e Desigualdades Sociais na Região Metropolitana de Belo Horizonte”. Centro de Estudos Municipais e Metropolitanos/Escola de Governo, FJP, Belo Horizonte, 1999.

HUNTINGTON, Samuel P. "Pretorianismo e Decadência Política”. In: CARDOSO, Fernando Henrique \& MARTINS, Carlos Estevam (orgs). Política e Sociedade. São Paulo, Ed. Nacional, 1979.

LIJPHART, Arend (1989). As Democracias Contemporâneas. Lisboa, Ed. Gradiva.

MANIN, Bernard; PRZEWORSKI, Adam \& STOKES, Susan C. (orgs.). Democracy and Accountability. New York, Cambridge University Press, 2000.

MATUS, Carlos. Política, Planejamento e Governo. Brasília, IPEA,1993.

MELO, Marcus André. "Governance e reforma do Estado: o paradigma agente X principal”. In: RSP, Revista do Serviço Público. Ano 47, vol. 120, n 1, Brasília, jan.-abr., 1996.

MELO, Marcus André. “Ingovernabilidade: Desagregando o Argumento". In: VALLADARES, Lícia do Prado (Org.). Governabilidade e Pobreza. Rio de Janeiro, Ed. Civilização Brasileira, 1995

MELO, Marcus André. The Politics fo Participatory budgeting (1985-1989). Mimeo, Recife, UEFPE/ BIRMLKGHAM/PROJECT, 2000.

O’DONNELL, Guillermo. "Sobre o Estado, a democratização e alguns problemas conceituais". In: Novos Estudos CEBRAP, nº 36, pp. 123-46, São Paulo, julho de 1993. 
OPUR, Observatório de Políticas Públicas da RMBH - PUCMINAS. “O Perfil dos Conselhos e Conselheiros Municipais da Região Metropolitana de Belo Horizonte”. Pesquisa vinculada ao Projeto PRONEX: "Metrópole, Desigualdade Sócio-Espacial e Governança Urbana: Rio de Janeiro, São Paulo e Belo Horizonte”. Coordenado pelo IPPUR /UFRJ, Belo Horizonte, 2001.

PIZZORNO, A. "Introduccion al Estudio de la participación Politica". In: PIZZORNO, KAPLAN e CASTELLS. Participación e Cambio Social en la Problematica Contemporanea. Buenos Aires, Ed. SIAPE, 1966.

PREFEITURA MUNICIPAL DE BELO HORIZONTE. Plano Diretor de Belo Horizonte — Projeto de Lei. Belo Horizonte, 1995.

PREFEITURA MUNICIPAL DE BELO HORIZONTE. Projeto de Lei de Parcelamento, Uso e Ocupação do Solo de Belo Horizonte. Belo Horizonte, 1995

PRZEWORSKI, Adam. "Reforma do Estado. Responsabilidade Política e Intervenção Econômica”. In: RBCS, Ano 11, n 32, pp. 18-40, outubro de 1996.

PRZEWORSKI, Adam. Estado e Economia no Capitalismo. Rio de Janeiro, Ed. Relume-Dumará, 1995. SANTOS JUNIOR, Orlando. "Democracia e Governo Local: dilemas da reforma municipal no Brasil".

Rio de Janeiro, UFRJ/Instituto de Pesquisa e Planejamento Urbano e Regional — IPPUR, 2001 (Tese, Doutorado em Planejamento Urbano e Regional).

SANTOS, Maria Helena de Castro. "Governabilidade e Governança: criação de capacidade governativa e o processo decisório no Brasil pós-constituinte". In: XX ENCONTRO ANUAL DA ANPOCS. Caxambú, outubro de 1996.

SANTOS, Maria Rosimary Soares. Caminhos Municipais da Cidadania: mudança institucional e democratização no Brasil. UFMG/ Departamento de Ciência Política-DCP, 1996 (Dissertação, Mestrado Ciência Política).

SANTOS, Mauro Rego Monteiro. Conselhos Municipais: a participação cívica na gestão das políticas públicas. Rio de Janeiro: UFRJ/Instituto de Pesquisa e Planejamento Urbano e Regional IPPUR, 2000 (Dissertação, Mestrado em Planejamento Urbano e Regional).

SANTOS, Mônica Regina dos. As Comissões Municipais de Emprego em Minas Gerais: Um Arranjo Neocorporativo de Aprimoramento Democrático? DCP-UFMG, junho de 2000, (Dissertação de Mestrado).

SANTOS, Wanderley Guilherme dos. "Gênese e Apocalipse: elementos para uma teoria da crise institucional latino-americana”. In: Novos Estudos CEBRAP, n 20, São Paulo, março de 1988.

SARTORI, G. A Teoria da Democracia Revisitada. 1. O Debate Contemporâneo. São Paulo, Ática, 1994.

SOMARRIBA, Mêrces \& DULCI, Otavio. "A Democratização do Poder Local e seus Dilemas: a dinâmica atual da participação popular em Belo Horizonte”. In: DINIZ, Eli \& AZEVEDO, Sérgio de (orgs.) Reforma do Estado e Democracia no Brasil. Brasília, UnB/ENAP, 1997.

STARK, David e BRUSZT, Laszlo. "Enabling Constraints: Fontes Institucionais de Coerência nas Políticas Públicas no Pós-Socialismo”. In: Revista Brasileira de Ciências Sociais, vol. 13, n 36, pp. 13-39, 1998.

STOKES, Susan C. "Democratic Accountability and Policy Change. Economic Policy in Fujimori's Peru”. In: Comparative Politics, vol. 29, n 2, pp. 209-26, 1997.

TSEBELIS, George. Nested Games. Rational Choice in Comparative Politics. Berkeley/Los Angeles, The University of California Press, 1990. 